\title{
Effects of LAN and Manager Characteristics on Perceived Issues of Concern for LAN Managers: The Distinctive Impact of...
}

Article in Journal of Organizational and End User Computing · January 1993

DOI: 10.4018/joeuc.1993100103

CITATIONS

0

1 author:

\section{Rajesh Mirani}

University of Baltimore

28 PUBLICATIONS 551 CITATIONS

SEE PROFILE

Some of the authors of this publication are also working on these related projects:

Project (To be Decided) View project 


\title{
Effects of LAN and Manager Characteristics on Perceived Issues of Concern for LAN Managers: The Distinctive Impact of Budget ${ }^{1}$
}

\author{
RAJESH MIRANI \\ University of Baltimore
}

\begin{abstract}
This paper reports the perceived problems, issues, or concerns of eighty-one LAN managers surveyed in as many U.S. corporations. The most frequently perceived issues were: managing LAN capacity or coordinating LAN users, setting up access rights or user accounts, planning LAN growth, ensuring $L A N$ reliability and uptime, ensuring good LAN performance and response time, and training and educating users. For individual managers, the total number of issues they perceived was not influenced by their job-related characteristics. It was, however, strongly and positively influenced by annual LAN budget. In turn, LAN budget was very strongly dependent on LAN size. However, the association between LAN size and number of issues perceived, although significant, was not as strong. The paper concludes that there exists a causal chain wherein only annual LAN budget directly affects the perceived issues of LAN managers. The implications for information systems executives and top management are discussed.
\end{abstract}

The future of end-user computing (EUC) depends on the abilities of functional managers to manage various EUC resources efficiently. Of these resources, local area networks (LANs) are an important and rapidly growing component. It is estimated that the worldwide market for all data communications products and services grew by 16 percent in 1992 despite the recession (Wilde, 1992). Further, LAN downtime now greatly affects business revenues in many organizations (Tittel, 1991).

There is an abundance of technical literature on LANs. However, there is scant research focusing on the problems, concerns, or issues perceived by LAN managers. The importance of LAN management is underscored by a recent Datamation survey (Marion, 1992) which revealed that LAN management applications were the most popular of all applications among IS professionals nationwide. Its importance is also evidenced by the exploding industry demand for LAN managers (Winkler, 1989).

Despite the abundance of technical literature on LANs, not much is known about the problems, concerns, and issues perceived by LAN managers. The activities involved in LAN management can be so numerous and complex that many network administrators these days barely have time to perform day-to-day maintenance activities (Sloman, 1991). A notable study in this regard was conducted by Nath (1988), who interviewed and surveyed thirteen LAN managers to identify, among other aspects, the perceived benefits and problems of

Manuscript originally submitted January 19, 1993; Accepted April 30, 1993 for publication. 
LAN managers. In a later paper, the same author reported the impact of LANs on users and their work (Nath, 1990).

However, much of the other published literature on network management consists of prescriptive papers (e.g., Buerger, 1988; Liang, 1988; Barrett, 1989; Janssens and Boone, 1989), anecdotal case studies of LANs in a few organizations (e.g., White, 1986; Buckler, 1987; Fersko-Weiss, 1987; Musich, 1987), or empirically unvalidated inferences about network administration (e.g., Durr 1985).

The goals of this research were to acquire a better understanding of the activities and problems, issues, or concerns of LAN managers by surveying a large cross-section of organizations, and to examine whether the number of problems, issues, or concerns perceived is dependent on the characteristics of LANs or those of LAN managers.

\section{Methodology}

Data collection for this study was conducted by means of a questionnaire survey designed for LAN managers. The instructions for the questionnaire re- quested the respondents to answer all questions in the context of the LAN managed by them. If their responsibilities included the management of more than one LAN, they were requested to answer all questions in the context of the largest LAN they managed.

Of the several questions included in the questionnaire, one set of questions was designed to assess characteristics pertaining to the LAN such as age of the LAN, number of users, applications used, existence of chargeback to users for LAN usage, annual LAN budget, and the provision of formal LAN training by the LAN manager to users.

A second set of questions was designed to assess various characteristics of the LAN manager, such as duration of tenure in current organizational position, annual salary, nature of the job (full-time vs. part-time), formal LAN management training/certification, internal or external assistance provided in LAN management, and involvement in planning/installation of the LAN.

A separate question asked LAN managers to list the "most important problems/concerns/issues that you perceive in managing this LAN."

One questionnaire was mailed to each seniormost IS executive of 509 of the top 1000 U.S. corpora-

\begin{tabular}{|c|c|c|c|c|}
\hline \multirow[b]{2}{*}{ Percentile } & \multicolumn{4}{|c|}{ LAN Characteristic } \\
\hline & $\begin{array}{l}\text { No. of } \\
\text { Users }\end{array}$ & $\begin{array}{l}\text { No. of } \\
\text { Nodes }\end{array}$ & $\begin{array}{l}\text { Budget } \\
\text { (\$ thousand) }\end{array}$ & $\begin{array}{l}\text { Age } \\
\text { (months) }\end{array}$ \\
\hline Mean & 366.65 & 319.31 & 255.26 & 34.82 \\
\hline \multicolumn{5}{|l|}{ Percentiles: } \\
\hline 0 & 5.00 & 7.00 & 2.50 & 0.00 \\
\hline 25 & 45.00 & 32.50 & 17.50 & 17.25 \\
\hline 50 & 120.00 & 65.00 & 61.00 & 33.00 \\
\hline 75 & 324.50 & 291.50 & 302.25 & 48.00 \\
\hline 100 & 4000.00 & 4000.00 & 1000.00 & 102.00 \\
\hline
\end{tabular}

Table 1: LAN Characteristics

Application

Word Processing

Spreadsheets

Electronic Mail

Graphics

File Transfer

Databases/Inquiry-Response

Data Entry

Transaction Processing

Mainframe Communication

Applications development

Project Management

Other
Percentage of LANs Running Application

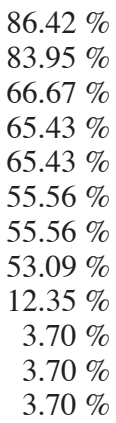

$86.42 \%$

$83.95 \%$

$65.43 \%$

$55.56 \%$

$55.56 \%$

$3.70 \%$

$3.70 \%$

Table 2: Applications Used on LANs 
tions privately held and traded on the New York and American Stock Exchanges. These 1000 corporations are listed in the Corporate Yellow Book published by Monitor Publishing Company (Gibbons, 1992).

A cover letter requested each executive receiving this questionnaire to forward it to the person with the responsibility of the ongoing management of any LAN in the organization.

\section{Responding Organizations}

Eighty-one questionnaires were completed and returned. This amounts to a response rate of $15.9 \%$, which is typical of survey studies where respondents are indirectly contacted through their organizational colleagues, and when there is no prior agreement with the surveyed organizations for their participation in the study. Moreover, as descriptive data presented in Table 1 and Table 2 reveals, the responding LANs were distributed across a wide spectrum in terms of their size, age, budget, and applications. Therefore, they are representative of the overall "population" of LANs, and the results from analyses of the data obtained from these LANs may be generalized to LANs universally.

Many organizations returned the entire packet mailed to them, citing the reason that they did not have any local area networks. Given the fact that local area networks constitute a relatively new technology, it is highly probable that there were many other organizations who did not respond for the same reason.

Some other organizations returned the packets mailed to them, citing the reason that it was against company policy to respond to surveys.

\section{Results}

\section{Issues Identified}

There were numerous different problems, concerns, or issues that respondents perceived in their LAN management activities. An exhaustive list of twenty-six issues mentioned by respondents, ordered by frequency of mention, is provided in Table 3. The issues most frequently mentioned were: managing capacity/coordinating LAN users, setting up access rights or new user accounts, planning future growth of LAN, ensuring high LAN reliability and uptime, ensuring good LAN performance and response time, and training and educating users on LAN issues.

For each respondent, the total number of problems, issues, or concerns identified (of those in the list in Table 3) were summed up to yield a total score. Since the maximum number of issues identified by any respondent

\section{Description of Issue}

Managing capacity/coordinating LAN users

Setting up access rights or new user accounts

Planning future growth of LAN

Ensuring high LAN reliability and uptime

Ensuring good LAN performance and response time

Training and educating users on LAN issues

Planning for disaster recovery

Preventing equipment and software obsolescence

Maintaining standardization/compatibility

Ensuring user satisfaction

Managing network files and data

Connecting LAN to host computers and other networks

Tracking LAN inventory

Hiring and training other LAN management personnel

Ensuring good vendor support

Customizing new applications to LAN

Managing user expectations/perceptions of LAN

Creating network documentation

Acquiring good administrative tools to automate tasks

Preventing software viruses on LAN applications

Replacing LAN cabling

Implementing LAN performance measurement tools

Accounting for network usage

Maintaining hardware components and spare parts

Finding software with features for LAN support

Garnering management support for LAN

\section{Number of Respondents}

Perceiving Issue

17
16
15
14
13
12
8
8
7
7
7
7
6
6
5
5
5
4
4
3
3
2
2
2
2
2

Table 3: Problems/Concerns/Issues of LAN Managers 
was 6 , and the minimum number 0 , this total score empirically varied from 0 to 6 for respondents. The total score will henceforth be referred to as "perceived task difficulty" since it represents a measure of the degree of difficulty of their jobs as perceived by LAN managers.

Analyses were carried out to determine whether perceived task difficulty was influenced by the LAN characteristics or LAN managers characteristics mentioned earlier. The following describes the results of these analyses.

\section{Effects of LAN Characteristics}

LAN Age. A Pearson correlation analysis was carried out to examine the effect of LAN age on perceived task difficulty. The resulting correlation coefficient was $0.1025(p<0.18)$. Since this was not significant, there was no evidence that LAN age affects perceived task difficulty.

LAN Size. In order to examine the possible influence of LAN size on perceived task difficulty, LAN size was measured by two methods: number of LAN nodes and number of LAN users. The correlation of number of LAN nodes with perceived task difficulty yielded a coefficient of $0.2338(p<0.02)$. Thus, this correlation was positive and significant, implying that the more the number of nodes in a LAN, the more the number of issues perceived by LAN managers. On the other hand, the correlation between number of LAN users and perceived task difficulty was 0.1703 ( $p<$ $0.07)$, thereby implying a very weak correlation. Thus, perceived task difficulty is evidently not as significantly influenced by number of LAN users as it is by the size of the physical network.

Number of Applications. Another correlation analysis examined the relationship between the number of LAN applications and perceived task difficulty. This yielded a positive and significant correlation $(r=0.2795$, $p<0.00)$. This implies that the higher the number of different applications on the LAN, the greater the perceived task difficulty on the part of the LAN manager.

Chargeback. A Student's $t$-test was conducted to examine whether the existence of a chargeback system to users for LAN usage affected perceived task difficulty of the LAN manager. Since the resulting $t$ statistic was not significant (Table 4), there was no evidence that chargeback had anything to do with perceived task difficulty.

Annual LAN Budget. The possible influence of annual LAN maintenance budget on perceived task difficulty was examined by means of a Pearson correlation. The resulting correlation coefficient was very strongly positive and significant for the 20 LANs that had a distinct maintenance budget allocated to them, separately from other information systems expenditures $(r=0.555, p<0.00)$. This suggests that the higher the annual LAN maintenance budget, the greater the perceived task difficulty of LAN managers.

A testable implication of the above result is that the perceived task difficulty for managers of LANs with their own annual budgets, distinct from other IS expenditures, will be greater than that for managers of LANs that are not allocated separate annual maintenance budgets. This was tested by means of a $t$-test. The difference in the mean value of perceived task difficulty for the two

\begin{tabular}{|c|c|c|c|c|}
\hline Category & $\begin{array}{l}\text { Sample } \\
\text { Size }\end{array}$ & Mean & $t$ & $\begin{array}{c}p \\
\text { (two-tailed) }\end{array}$ \\
\hline & & & -0.10 & 0.10 \\
\hline No Chargeback & 60 & 2.30 & & \\
\hline Chargeback & 18 & 2.30 & & \\
\hline
\end{tabular}

Table 4: Effect of Chargeback on Perceived Task Difficulty of LAN Managers

\begin{tabular}{|llccc|}
\hline & & & & \\
Category & Sample & Mean & $\boldsymbol{t}$ & $\begin{array}{c}\boldsymbol{p} \\
\text { (two-tailed) }\end{array}$ \\
& Size & & -2.91 & 0.00 \\
No Separate Budgets & 61 & 2.08 & & \\
Separate Budgets & 20 & 2.95 & \\
\end{tabular}

Table 5: Effect of Annual LAN Maintenance Budgets on Perceived Task Difficulty of LAN Managers 
groups of LANs was found to be statistically significant (Table 5). The results of the analysis imply that the presence of a distinct annual maintenance budget for LANs is likely to increase the perceived task difficulty of LAN managers.

Since the effects of both LAN size (as measured by number of nodes) and annual budget on perceived task difficulty were found to be strong and positive, a Pearson correlation was conducted to determine the extent of correlation between annual budget and number of LAN nodes. The correlation was $0.8736(p<0.00)$, implying that the two are very strongly and positively correlated to each other.

User Training. A Student's $t$-test was carried out to examine whether perceived task difficulty was different for LAN managers who provided their users with some form of training from those managers who did not provide any training to their users. The resulting $t$ statistic was not significant (Table 6). This implies that provision of training by LAN managers to users does not affect perceived task difficulty of LAN managers.

\section{Effects of LAN Manager Characteristics}

Duration of Tenure. A Pearson correlation analysis was conducted to examine whether perceived task difficulty of LAN managers varied significantly with the total time (months) in their current organizational position. The correlation coefficient $(r=-0.1312$, $p<0.12$ ) was not significant, thereby implying that perceived task difficulty of LAN managers does not vary with the length of tenure in their current organizational position.
Annual Salary. Another Pearson correlation was conducted to examine any possible influence of annual salary of LAN manager on perceived task difficulty. There was no evidence of such a relationship as the resulting correlation coefficient $(r=0.0938, p<0.22)$ was not significant.

Nature of Job. A $t$-test was carried out to test whether full-time LAN managers differed from parttime LAN managers on perceived task difficulty. Once again, there was no evidence of a significant difference (Table 7).

Formal LANManagement Training. LAN managers in many organizations are known to attend professional development courses that prepare them for a certification in LAN management. Such courses are offered by various vendors of LANs, such as Novell, for example. A $t$-test was conducted in order to examine whether LAN managers who had undergone such formal training in LAN management had different levels of perceived task difficulty from LAN managers who did not have such formal training in LAN management. The results imply that there is no significant difference in perceived task difficulty due to formal LAN management training (Table 8).

Internal and External Assistance. In many organizations, LAN managers are assisted in their work by other internal organizational personnel, or by external parties such as vendors or consultants. An analysis of variance (ANOVA) was conducted to determine whether the presence of such assistance influenced perceived task difficulty. Only 2 of the 81 respondents had both internal as well as external assistance, and hence the

\begin{tabular}{|lcccc|}
\hline Category & Size & Mean & $\boldsymbol{p}$ & $\begin{array}{c}\boldsymbol{p} \\
\text { (two-tailed) }\end{array}$ \\
& & & 0.61 & 0.54 \\
No User Training & 35 & 2.40 & & \\
User Training & 43 & 2.23 & \\
\end{tabular}

Table 6: Effect of User Training on Perceived Task Difficulty of LAN Managers

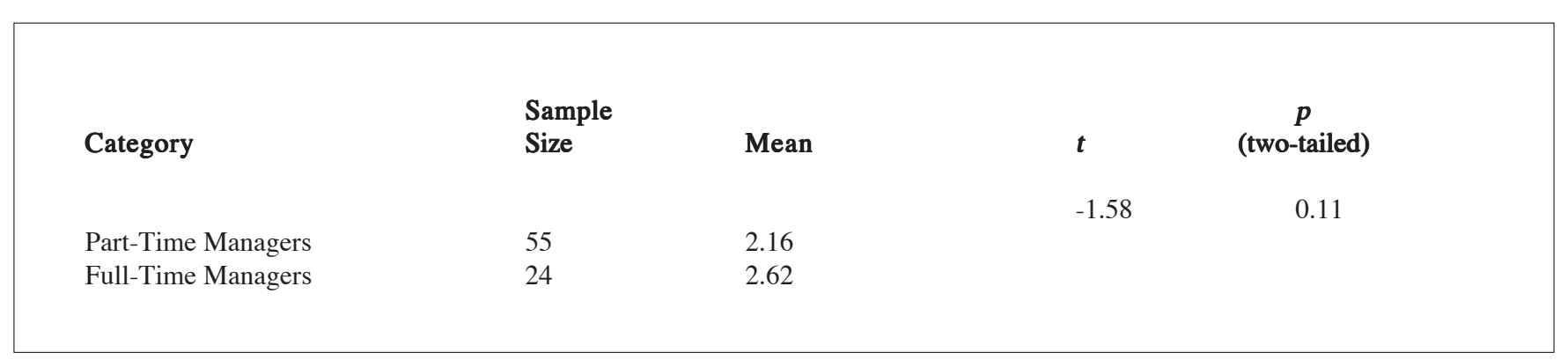

Table 7: Perceived Task Difficulty: Part vs. Full Time LAN Managers 


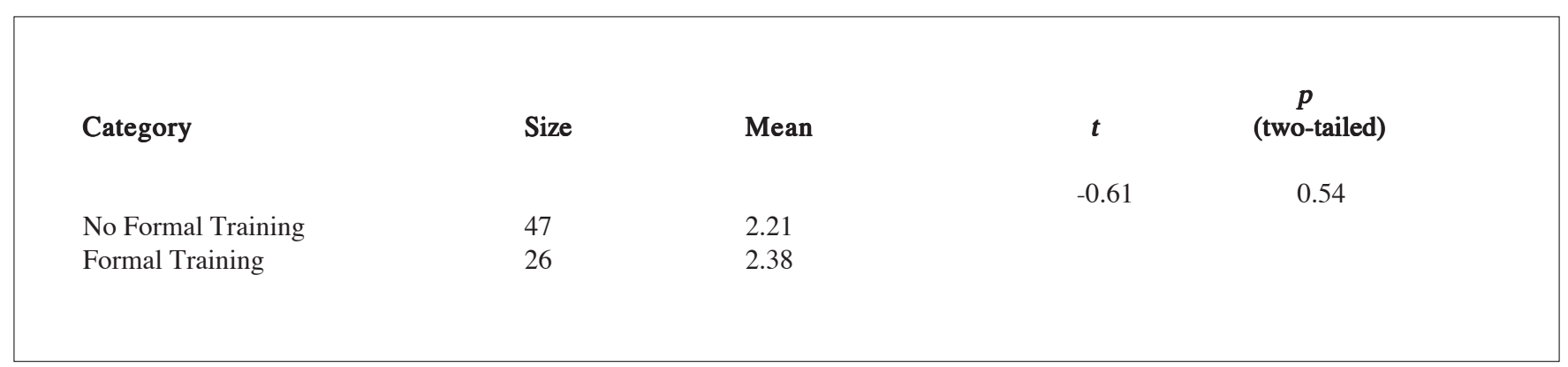

Table 8: Effect of Formal LAN Management Training on Perceived Task Difficulty of LAN Managers

\begin{tabular}{|c|c|c|c|c|}
\hline Category & $\begin{array}{l}\text { Sample } \\
\text { Size }\end{array}$ & Mean & $F$ & $\begin{array}{c}p \\
\text { (two-tailed) }\end{array}$ \\
\hline & & & 0.06 & 0.94 \\
\hline No Assistance & 39 & 2.23 & & \\
\hline Internal Assistance Only & 27 & 2.30 & & \\
\hline External Assistance Only & 11 & 2.36 & & \\
\hline
\end{tabular}

Table 9: Effect of Internal and External Assistance on Perceived Task Difficulty of LAN Managers

\begin{tabular}{|c|c|c|c|c|}
\hline Category & $\begin{array}{l}\text { Sample } \\
\text { Size }\end{array}$ & Mean & $t$ & $\underset{\text { (two-tailed) }}{p}$ \\
\hline & & & 1.45 & 0.15 \\
\hline No Involvement & 16 & 2.68 & & \\
\hline Involvement & 61 & 2.19 & & \\
\hline
\end{tabular}

Table 10: Effect of Involvement in LAN Planning/Installation on Perceived Task Difficulty of LAN Managers

ANOVA was limited to three groups of respondents: those with no assistance, those with internal assistance only, and those with external assistance only. The results of the analysis reveal that the presence of internal or external assistance does not significantly affect perceived task difficulty (Table 9).

Involvement with Planning/Installation. Of the 81 respondents, 61 indicated that they had been involved with the planning or installation of the LAN they currently managed. A $t$-test was conducted to examine whether managers who had been involved in the planning or installation of their LANs in some manner differed in their perceived task difficulty from managers who had no such involvement in the inception of their LANs. The resulting $t$-statistic was not significant, implying that such involvement did not significantly influence perceived task difficulty (Table 10).

\section{Summary of Effects}

To summarize, of the various characteristics tested for their impact on perceived task difficulty of LAN managers, annual budget, size (as represented by number of nodes), and number of applications were found to have significant impacts (Table 11).

\section{Discussion and Implications}

This research has identified the various problems and issues perceived by LAN managers and analyzed the pervasiveness of these issues. A few years ago, the major issues of concern for LAN managers used to be: lack of security, lack of networkable software, the need for an in-house LAN maintenance person, incompatibility of equipment, and lack of managerial training on LANs (Nath, 1988). However, these issues seem to have lessened in importance over time, perhaps because they have been somewhat resolved in many organizations. Instead, the most pressing issues today have to do with making the best use of LAN capacity, maximizing 


\section{Characteristic}

LAN Characteristics

Age

Number of nodes

Number of users

Number of applications

Chargeback

Annual LAN budget

User Training

LAN Manager Characteristics

Duration of tenure

Annual salary

Nature of job

Formal LAN management training

Internal or external assistance

Involvement in LAN planning/

installation
Impact on Perceived

Task Difficulty

Not significant

Positive $(r=0.2338, p<0.02)$

Not significant

Positive $(r=0.2795, p<0.00)$

Not significant

Positive $(r=0.5550, p<0.00)$

Not significant

Not significant

Not significant

Not significant

Not significant

Not significant

Not significant

Table 11: Summary of Impacts of Various LAN and Manaager Characteristics on Perceived Task Difficulty

reliability and operating speed, planning for future LAN growth, and training and educating users. This information should help IS executives in planning for LAN management.

This study demonstrated that although perceived task difficulty of LAN managers is significantly affected by certain LAN characteristics, it is not significantly affected by the job-related characteristics of the LAN managers. The implication of these results is that IS executives can look forward to a certain degree of predictability in planning for the management of LANs. This is because the issues or problems expected to be encountered in LAN management are dependent only on the characteristics of the LANs themselves and not those of the LAN managers.

Of the three LAN characteristics shown to have significant impacts on perceived task difficulty, annual LAN budget, not LAN size, is the most powerful predictor. This may be an unexpected outcome because intuition suggests that LAN size should be a predictor of both annual budget as well as perceived task difficulty. Yet, while LAN size was found to be strongly associated with annual budget, it was not as strongly associated with perceived task difficulty.

These results indicate the presence of a causal chain in which LAN size (number of nodes) is a determinant of annual budget, which, in turn, affects perceived task difficulty (Figure 1). Thus, perceived task difficulty is directly affected only by annual LAN budget and not

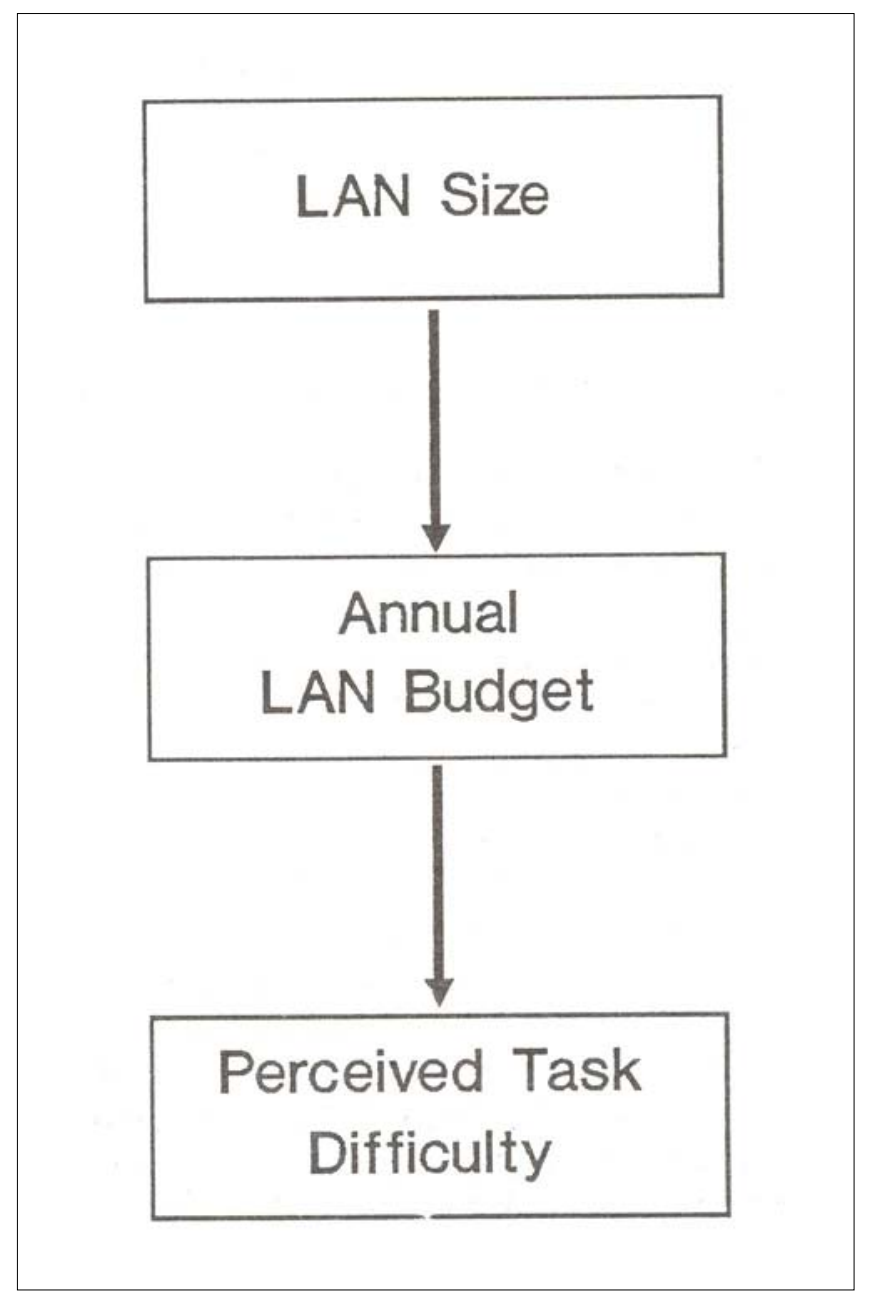

Figure 1: Probable Causal Model 
by LAN size.

The correlation coefficients obtained in this study support the proposed causal chain in Figure 1. Nevertheless, it is not feasible to conduct a formal path analysis to confirm this chain because path analysis programs such as LISREL require a very large number of observations or data points. Since only 20 organizations in this study had separate LAN budgets, such an analysis would not be appropriate.

However, there is evidence in the behavioral accounting literature that job-related tension among managers is higher when there is a greater budget emphasis in the evaluative styles of their superiors (Hopwood, 1972), particularly if managers perceive a high degree of task uncertainty (Hirst, 1983). This study has established that larger LANs are more likely to be allocated bigger and/or exclusive budgets. Perhaps LAN managers in general perceive a high degree of task uncertainty. This may explain the strong correlation found between annual LAN budget and perceived task difficulty in this study.

The major implications of these results are that LAN management is a complex activity fraught with diverse issues. Senior IS managers should educate top management on the need for recognizing and addressing these issues, and of their impact on organizational effectiveness and efficiency. Both IS management and top management should be aware that unless budgetary resources are adequately allocated, many of these issues will not even surface but will probably lie dormant, particularly in the case of large LANs. The extent to which these issues are confronted will affect the success of end-user computing and the effectiveness of the organization.

\section{Endnote}

${ }^{1}$ This study was supported in part by a research grant from the Merrick School of Business, University of Baltimore.

\section{References}

Barrett, K.E. (1989). Scaling the Heights. Network World, 6(45), 69, 79-80.
Buckler, G. (1987). Part-Time Network Management: Smaller LANs Require Less Time. Computing Canada, 13(5), 23-24.

Buerger, D.J. (1988). Are Full-Time Managers Really Necessary for PCBased LANs? InfoWorld, 10(14), 16.

Durr, M. (1985). Administration Revealed Micro Communications, 2(7), 3740.

Fersko-Weiss, H. (1987). Who Manages the Network? Personal Computing, 11(3), 107-115.

Gibbons, L. (1992). Ed., Spring 1992 edition, Corporate Yellow Book. New York: Monitor Publishing Company.

Hirst, M.K. (1983) Reliance on Accounting Performance Measures, Task Uncertainty, and Dysfunctional Behavior: Some Extensions. Journal of Accounting Research, 21(2), 596-605.

Hopwood, A.G. (1972). An Empirical Study of the Role of Accounting Data in Performance Evaluation. Journal of Accounting Research, 10(supplement), 156-182.

Janssens, G.K., \& Boone, C. (1989). Organization of Successful LAN Use. Journal of Systems Management, 40(2), 13-15.

Liang, T.-P. (1988). Local Area Networks: Implementation of Considerations. Journal of Systems Management, 39(1), 6-12.

Marion, L. (1992). The Hot Applications of 1992. Datamation, 38(10), 35-39.

Musich, P. (1987). LAN Caretaker Tackles Issues. Network World, 4(13), 2122.

Nath, R. (1988). Local Area Networks: The Network Managers' Perspective. Information and Management, 14(4), 175-181.

Nath, R. (1990). The Impact of Local Area Networks on Users and Their Work: A Field Study. Journal of Microcomputer Systems Management, 2(2), $15-23$.

Sloman, J. (1991). Automating Networking Management. LAN Technology, $7(7), 32-44$.

Tittel, E. (1991). Troubleshooting Keeps LANs Up and Running. Networking Management, 9(1), 54.

White, L. (1986). Putting Network Management into Good Hands. Computerworld, 20(2A), 41-43.

Wilde, C. (1992). The 1993 Data Comm Market Forecast. Data Communications, 21(18), 85-94.

Winkler, C. (1989). LANs Surge, So Does This Ad: Wanted, LAN Manager. Data Communications, 18(4), 61-69.

Rajesh Mirani is Assistant Professor in the Information and Quantitative Sciences Department, Merrick School of Business, University of Baltimore. He received his Ph.D. from University of Pittsburgh. His current research interests focus on the management of end-user computing, and the justification of proposed information systems projects. He has published in MIS Quarterly and is a frequent contributor to professional conferences. 


\section{Related Content}

How Does Attitude Impact IT Implementation: A Study of Small Business Owners

Elaine R. Winston and Dorothy Dologite (2002). Journal of Organizational and End User Computing (pp. 16 $-29)$.

www.irma-international.org/article/does-attitude-impact-implementation/3750/

The Reality of User-Centered Design

Susan Gasson (1999). Journal of End User Computing (pp. 5-15).

www.irma-international.org/article/reality-user-centered-design/55773/

Semantic Composition of Web Portal Components

Jens Jahnke, Yury Bychkov, D. Dahlem and L. Kawasme (2006). Journal of Organizational and End User Computing (pp. 66-87).

www.irma-international.org/article/semantic-composition-web-portal-components/3819/

Knowledge Transfer from Expert Systems vs. Traditional Instruction: Do Personality Traits Make a Difference?

Marcus D. Odom and Hamid Pourjalali (1996). Journal of End User Computing (pp. 14-20).

www.irma-international.org/article/knowledge-transfer-expert-systems-traditional/55727/

The Application of Job Rotation in End User Computing: Toward a Model for Research and Practice

Jo Ellen Moore (1997). Journal of End User Computing (pp. 4-14).

www.irma-international.org/article/application-job-rotation-end-user/55735/ 